\title{
Clinical Outcomes of Open Ventral Hernia Repair in a Public Sector Hospital
}

\author{
Syed Kashif Ali Shah, ${ }^{1}$ Gulshan Ali Memon, ${ }^{2}$ Khawar Saeed Jamali, ${ }^{3}$ Rafiq Ahmed Sahito, ${ }^{4}$ Habib- \\ ur-Rehman, ${ }^{5}$ Shahnawaz Leghari, ${ }^{6}$ Shahida Baloch ${ }^{7}$
}

\section{Abstract}

Objective: This prospective study was designed to see the outcomes in two different types of surgical repairs (suture or mesh) of primary ventral hernia.

Methods: A total of 70 adult patients under went for elective primary ventral hernia suture or mesh repair at surgical unit-I of Peoples Medical College Hospital Nawabshah and Surgical Unit-I from March-2010 to Feb-2016 were included in this study on the basis of inclusion - exclusion criteria. Patient's demographic characteristics, operative details, post-operative outcomes (complications and recurrence) were studied.

\footnotetext{
${ }^{1}$ Senior Registrar, Department of General Surgery, PUMHS, Nawabshah.

${ }^{2}$ Professor and Dean Surgery \& Allied, Department of General Surgery, PUMHS, Nawabshah.

${ }^{3}$ Professor of Surgery and Pro-Vice Chancellor Dow University of Health Sciences, Karachi.

${ }^{4}$ Associate Professor, Department of General Surgery, PUMHS,

Nawabshah.

${ }^{5}$ Assistant Professor, Department of General Surgery, PUMHS, Nawabshah.

${ }^{6}$ Department of General Surgery, PUMHS, Nawabshah.

${ }^{7}$ Postgraduate Trainee, Department of General Surgery, PUMHS, Nawabshah
}

Date of Submission: 20-03-2017

Date of $1^{\text {st }}$ Revision Received: 06-04-2017

Date of Acceptance for Publication: 24-04-2017

Conflict of Interest: None

Funding Source: None

\section{Contribution}

All Authors have contributed in Study Design, Data Collection, Data Analysis, Data Interpretation, Manuscript Writing and Approval.
Results: A total number of 70 consecutive patients having primary ventral hernia under went for an elective open repair either with suture $(32 / 45.7 \%)$ or synthetic mesh (38/54.3\%) were evaluated in this study. Among these patients $52(74.2 \%)$ and 18 (25.8\%) were female and male respectively, with mean age of $51.5 \pm$ 12. A total of 3(7.89\%) patients had recurrence with Mesh Repair and 06(18.75\%) with suture repair at 3 years follow-up, $\mathrm{p}$-value $=0.176$.

Conclusion: The mesh repair in ventral hernia has low wound complications and less recurrence of the hernia when compared with suture technique.

Key words: Umblical Hernia, Paraumblical Hernia, Epigastric Hernia, Herniorrhaphy, Hernioplasty.

\section{Introduction}

The fascial defects in anterior abdominal wall presenting with abnormal protrusion are termed as Ventral Hernia, which may be primary like epigastric, umbilical, para-umbilical, spigelian, lumbar etc or Secondary/acquired following trauma or surgery (incisional). ${ }^{1}$ The reconstruction of ventral hernia remains one of the most challenging dilemmas facing surgeons across the globe. The increasing incidents of ventral hernia among actively working young people of society puts a large burden of resource and cost on the health care system, as more than 386000 ventral hernia repair are noted annually even in much advanced country like America, among these $75 \%$ are primary ventral (Non-incisional) Hernias. ${ }^{2,3,4}$ Studies report that up to 3.2 billion dollars are spent there each year to repair ventral hernias. Despite the volumes of the literature on hernial repair, the meaningful rewarding interpretation cannot be explained due to the bundles of futile studies depicting combinations of surgical approaches 
complex techniques, and then choice of position and fixation of prosthesis. While peri-operative management is another debated issue. ${ }^{2}$

In addition, there is also no consensus on surgical site occurrence (SSO), known as complications and hernia recurrence as the most important end points in the repair of ventral hernia ${ }^{5}$. And in this regard, many studies report that the surgical site occurrence like seroma, Hematoma, surgical site infections (SSI), skin dehiscence, Skin necrosis, cellulitis and suture granuloma or abscess are abysmal risk factors associated with increased preponderance of recurrence of ventral hernia with or without mesh repair. ${ }^{6,7}$

Further, co morbidities like chronic use of corticosteroids, smoking, coronary artery disease, chronic artery disease, chronic obstructive pulmonary disease, diabetes, malnutrition, immuno suppression, low serum albumin, obesity and old age may convey at least four folds infection risk post-operatively as have been analyzed by National Surgical Quality Improvement Program (NSQIP). ${ }^{8-11}$

Indeed, the repair of Ventral Hernia with mesh acknowledges better outcomes in comparison to suture; hence surgical wisdom are choosing it as an optimal standard of care. ${ }^{6,12}$ But the relationship between hernia types Primary (Congenital) or Acquired (incisional) and profound $\mathrm{SSO} /$ Complications resulting morbidity and additional sequelae are not yet precisely delineated in available literature. ${ }^{13}$ This is so because the available studies are few randomized control trials limited with small numbers, short follow-up and vague end points without having assertion of principle of approaches in assessment and repair of various ventral hernia. ${ }^{14}$ The closure of fascial defect in ventral hernia with suture or mesh by open surgery remains the most common approach, accounting approximately $75 \%$ of cases. ${ }^{15}$ OVHR is still rewarding and common practice in resource limited institutions in general and at our part of world in particular. ${ }^{6}$ So in this perspective, this study was designed to access the outcomes (Recurrences) in two different surgical (suture or mesh) repairs of primary ventral hernia.

\section{Methods}

A total of 70 adult patients under went for Elective Primary Ventral Hernia Suture or Mesh repair at surgical unit-I of Peoples Medical College Hospital Nawabshah and Surgical Unit-I of from March-2010 to Feb2016 were included in this study on the basis of inclu- sion - exclusion criteria. The patients of both gender from 18 to 65 years of age with primary ventral hernia except lumbar with given informed consent and fit for general Anesthesia for open repair surgery were enrolled. While the patients having presence of more than one hernia, signs of infection, incisional or recurrent hernia, ascites, systemic disease like liver, renal failure, un controlled diabetes and patients under went in emergency surgery for incarcerated or strangulated hernia were excluded. All patient received appropriate pre-operative antibiotics along with anti-thrombotic prophylaxis as per need. The patient were approached through either midline or transverse incision under general anesthesia and after complete lysis of adhesions and resection of redundant soft tissue and skin, the size of hernial defect was measured and recorded. Patient having hernial defect up to $5 \mathrm{~cm}$ were under gone repair with suture, as the two edges of the fascia were approximated without tension with a continuous polypropylene suture No. 1, with stich width (Tissue bites) and intervals of $1 \mathrm{~cm}$ apart. While patients having hernial defect more than $5 \mathrm{~cm}$ were undergone with either inlay or sublay (Retromuscular Rives stoppa) mesh repair in which dorsal side of the fascia adjacent to the hernia was freed from under laying tissue for about $4-5 \mathrm{~cm}$. A polypropylene mesh was tailored in the defect to have about $4 \mathrm{~cm}$ of mesh overlapped on the edge of fascia and the placed mesh was reinforced with continuous suture of prolene No. 1 to the abdominal wall at least $3-4 \mathrm{~cm}$ away from the edge of defect. While the peritoneal defect was closed or omentum was sutured in between to avoid the contact of mesh with intraperitoneal gut and prevent any adhesion \& incident of fistula. ${ }^{16,17}$

The cavity of wound was irrigated with third generation cephalosporin antibiotic laden normal saline and closed suction drain(s) was (were) placed as per need. The anterior rectus sheath was re-approximated with mono filament sutures. Subcutaneous tissues were also irrigated with normal saline and were closed in layers. Sterile dressing was placed over the wound followed by abdominal binder and were shifted to ward. Post operatively every patient received third generation cephalosporin antibiotics and some of them remained on deep vein thrombosis prophylaxis during hospital stay. Liquid to regular routine diet were allowed accordingly as tolerated. Drains were removed when were without outputs. Patients were discharged after having adequate oral intake and pain controlled with oral analgesics and was asked for follow-up visits with clear instructions. Peri-operative data collection inclu- 
ded size of hernial defect, location (Upper or middle), type of surgical procedures (Prolene suture or mesh repair), operative duration determined by the time from skin incision to skin closure and length of hospitalization. Early-Post operative risk factors of SSO like symptomatic seroma, hematoma, SSIs, skin necrosis or wound dehiscence were recorded and SSI was defined as per definition of centers of disease control and prevention (CDC). ${ }^{17}$

While the followup outcomes of hernia recurrence rate were evaluated in both types of repair separately. The designed post-operative follow-up evaluation included physical examination at 4 week, 3 months, 6 months and then annually for one visit. Having excellent patient follow-up we believe the strengths of our study. Patient's awareness of recurrence were evaluated and noted. Patient with documented evidence of hernia (bulge) recurrence were not taken to have further evaluation in follow-up. The ultrasound examination or even CT Scan abdomen were taken in cases where physical examination to identify the recurrence were suspicious.

All data was entered in SPSS version 20. Mean and S.D was used for quantitative data like age years. Frequency (\%) was used for qualitative data, gender, type of ventral hernia, wound infection and recurrence. Chi-square test was applied to compare wound complications and recurrence in both study groups.

\section{Results}

A total number of 70 adult consecutive patients having primary ventral hernia under went for an elective open repair either with suture $(32 / 45.7 \%)$ or synthetic $(38 / 54.3 \%)$ were evaluated in this study. Among these patients $52(74.2 \%)$ and $18(25.8 \%)$ were female and male respectively, with mean age of 51.512 and BMI more than $30 \mathrm{~kg} / \mathrm{m}^{2}$ is seen in 20 patients $(\mathrm{F} / 18, \mathrm{M} / 2)$. While 10 were smokers (F/2. M/8), many patients had associated co-morbidities like $18(\mathrm{~F} / 16 . \mathrm{M} / 2)$ had diabetes mellitus with a mean $\mathrm{Hb} \mathrm{A} / \mathrm{C}$ value of $8.1 \%$ and $5(\mathrm{~F} / 1 . \mathrm{M} / 4)$ were suffering from COPD. The mean range of American society of anesthesiologist score was $2-8$. All these patients are briefed in table No: 1 for their demographic and pre-operative characteristics.

Table 1:

\begin{tabular}{|l|c|c|}
\hline \multirow{2}{*}{\multicolumn{1}{c|}{ Particulars }} & \multicolumn{1}{c|}{ DATA } & \\
\cline { 2 - 3 } & No. of Patients & $\%$ \\
\hline Female (F) & 52 & $74.2 \%$ \\
\hline Male (M) & 18 & $25.8 \%$ \\
\hline Age (mean) & $51.5 \pm 12$ & \\
\hline Female: male ratio & $2.8: 1$ & \\
\hline Obesity (BMI) $30 \mathrm{~kg} / \mathrm{m}^{2}$ & 20 & $28.5 \%$ \\
\hline Smokers & 10 & $14.3 \%$ \\
\hline Diabetes Mellitus & 18 & $25.7 \%$ \\
\hline COPD & 5 & $7.14 \%$ \\
\hline
\end{tabular}

COPD (chronic obstructive pulmonary disease)

Among these patients, the majority presented with umbilical hernia (32), then (23) as paraumblical, 13 had epigastric and 02 (female) had spigelian hernia. The median length of hospital stay was 8 days (range 6 to 29 days).

All these focused hernia findings are briefed in table no 2.

Table 2:

\begin{tabular}{|l|c|c|c|c|c|c|c|}
\hline \multirow{2}{*}{\multicolumn{1}{|c|}{ Particulars }} & \multicolumn{3}{|c|}{ Mesh Repair } & \multicolumn{4}{c|}{ Suture Repair } \\
\cline { 2 - 8 } & UH & PUH & EH & UH & PUH & EH & Spig \\
\hline Normal wound & 05 & 06 & 03 & 18 & 11 & 09 & 02 \\
\hline Infected wound & 02 & 02 & 00 & 8 & 09 & 01 & 00 \\
\hline Sero-sanguineus Discharge & 01 & 01 & 00 & 04 & 02 & 01 & 00 \\
\hline Wound dehiscence & 00 & 1 & 00 & 02 & 01 & 00 & 00 \\
\hline
\end{tabular}




\begin{tabular}{|l|l|l|l|l|l|l|l|l|}
\hline \multirow{3}{*}{ Recurrence } & $1^{\text {st }}$ year & 01 & 01 & 00 & 02 & 01 & 00 & 00 \\
\cline { 2 - 9 } & $2^{\text {nd }}$ year & 00 & 01 & 00 & 02 & 02 & 00 & 00 \\
\cline { 2 - 9 } & $3^{\text {rd }}$ year & & 00 & 01 & 01 & 01 & 00 & 00 \\
\hline & & 03 & & 06 & & & \\
\hline
\end{tabular}

$\mathrm{p}$-value for recurrence, $\mathrm{p}$-value $=0.176$.

Among 70 patients, $32 \& 38$ underwent Simple Suture and sublay synthetic Mesh Repair respectively. In both repairs 9 (12.8\%) patient outcome with recurrence. From these 09 patients, 03 were male and 06 were females. While, from 38 patients having Mesh Repair 03 (8\%) had recurrence; and, from 32 patients having Simple Suture Repair 06 (18.7\%) had recurence.

\section{Discussion}

As the surgical literature is lacking in data that compare the recurrence rates between open traditional suture repair versus synthetic mesh repair in primary ventral hernia over a long term followup. ${ }^{18}$ Therefore the gold standard approach for ventral hernia repair remains to be an area of controversy. ${ }^{19}$ Despite of best practices, hernia recurrence remains a significant challenge and the use of synthetic meshes has decreased the incidence of ventral hernia recurrence. ${ }^{20}$ In this study, majority of the patients were considered to be at increased risk of wound complications and recurrence because of their pre-existing co-morbid conditions, and hence, through this study, it was vigilantly focused on various co-morbid conditions for their association with increased rate of recurrence. The conditions that seem to be associated in this regard were obesity, and COPD (Asthma). And this study corresponds in similarity to the studies of Kapata DM etal. ${ }^{21}$ In our study the rates and types of postoperative complications are very similar to marry as quoted in literature. ${ }^{22,23}$

This study, observed that surgical site infection (SSI) is the most common risk factor for a reason of recurrent hernia, this is in the line with other studies that have also shown it to be predictive of future recurrence. In research it was demonstrated that any degree of post operative infection (SSI) can lead to potential complication with consequent mesh removal. Despite the significant SSI, there were two patients who require mesh removal and this corresponding similarity is also with study of Farrow B, et al. ${ }^{22}$ Thus decreasing the rates of SSI with ventral hernia repair will alleviate the surprising high rates of recurrence. ${ }^{23}$

While, some propose that the use of laparoscopy reduces SSI rates compared with open repair. ${ }^{23,24} \mathrm{An}$ otherwise study suggests that increased use of mesh repair in every primary ventral hernia will prevent the successive incisional hernia. ${ }^{25-27}$

This study finds that most of the recurrence after both open suture or mesh repairs occur in two year of surgery and this is very similar to study of Ngnyen MT et al. ${ }^{29}$ While many other studies have compared recurrence rates in various procedures of open ventral hernia repair but there subjects and follow-up period were too small to persuade the connotation of recurrence. ${ }^{29}$ Ngnyen MT, et al and Porrero JI, et al found in their studies that suture repair is appropriate for small primary ventral hernia with acceptable recurrence rates of less than $10 \%$, while our study finds higher rates of recurrence $(18.7 \%)^{29,30}$ and this makes to think that the size of defect should not be more than $3 \mathrm{~cm}$ in simple suture repair. Generally in open ventral hernia repair, there are higher rates of post-operative SSI, which varies from technique to technique and mesh positions. ${ }^{31,32}$ Hence, Mesh (synthetic or Biologic) selection, as does its position (sublay, inlay or onlay) and technique of mesh fixation varies widely from surgeon to surgeon. ${ }^{33}$ However, in this study, patients having ventral hernia defect more than $5 \mathrm{~cm}$ were subjected to sublay/retromuscular mesh placement, and this study found the recurrence rate of $8 \%$ which corresponding to other studies as shown below.

\section{Conclusion}

The mesh repair in ventral hernia has low wound complications and less recurrence of the hernia when compared with suture technique. 
Table 3: Comparison of results of different studies.

\begin{tabular}{|l|l|l|l|l|l|l|l|}
\hline \multicolumn{1}{|c|}{ Author } & \multicolumn{1}{|c|}{ Year } & Study Type & \multicolumn{1}{|c|}{$\mathbf{N}$} & $\begin{array}{c}\text { Follow-up } \\
\text { (Months) }\end{array}$ & *SSO & **SSI & Recurrence \\
\hline Rives & 1992 & $* * * \mathrm{R}$ & 258 & & & $7.7 \%$ & $6.2 \%$ \\
\hline McLanahan & 1997 & $\mathrm{R}$ & 106 & 24 & & & $3.5 \%$ \\
\hline Petersen & $\mathrm{R}$ & $\mathrm{R}$ & 175 & 20 & $7.4 \%$ & $6.3 \%$ & $9.0 \%$ \\
\hline Israelsson & 2006 & $\mathrm{R}$ & 228 & $12-24$ & & & $7.3 \%$ \\
\hline Iqbal & 2007 & $\mathrm{R}$ & 254 & 70 & $4.0 \%$ & $7.0 \%$ & $5.0 \%$ \\
\hline Poghoysan & 2012 & $\mathrm{R}$ & 262 & 58 & $6.0 \%$ & $0.8 \%$ & $3.0 \%$ \\
\hline Mehrabi & 2010 & $\mathrm{R}$ & 176 & 96 & $1.7 \%$ & $2.8 \%$ & $1.1 \%$ \\
\hline Novitsky & 2015 & $* * * * \mathrm{P}$ & 306 & & $11.8 \%$ & $15.7 \%$ & -- \\
\hline Cobb & 2015 & $\mathrm{R}$ & 255 & 17 & $37.7 \%$ & $19.6 \%$ & $16.9 \%$ \\
\hline Kashif & 2017 & $\mathrm{P}$ & 70 & 36 & $31.42 \%$ & $18.6 \%$ & $8 \%$ \\
\hline
\end{tabular}

Follow-up

* Surgical Site Occurrence

**Surgical Site Infection

\section{$* * *$ Retrospective}

$* * * *$ Prospective

\section{References}

1. Burger J, Luijendijk RW, Hop W, Halm JA, Verdaasdonk EG, Jeekel J. Long-term follow-up of a randomized controlled trial of suture versus mesh repair of incisional hernia. Ann Surg. 2004; 240: 578-83.

2. Poulose BK, Shelton J, Phillips S. Epidemiology and cost of ventral hernia repair: making the case for hernia research. Hernia, 2012; 16: 179-83.

3. Kokotovic D, Sjølander H, Gögenur I, Helgstrand F. Watchful waiting as a treatment strategy for patients with a ventral hernia appears to be safe. Hernia, 2016: Feb. 2, Epub ahead of print.

4. Muysoms FE, Miserez M, Berrevoet F, Campanelli G, Champault GG, Chelala E, et al. Classification of primary and incisional abdominal wall hernias. Hernia, 2009; 13 (4): 407-14.

5. Christmas AB, Reynolds J, Wilson AK, Franklin GA, Miller FB, Richardson JD, Rodriguez JL. Morbid obesity impacts mortality in blunt trauma. The American surgeon, 2007; 73 (11): 1122-5.

6. Nguyen MT. Comparison of outcomes of synthetic mesh vs. suture repair of elective primary ventral herniorrhaphy: a systematic review and meta-analysis. JAMA Surg. 2014; 149 (5): 415-421.

7. Berger RL et al. Suture versus preperitoneal polypropylene mesh for elective umbilical hernia repairs. J Surg Res. 2014; 192 (2): 426-431.

8. Dunne JR, Malone DL, Tracy JK, Napolitano LM. Abdominal wall hernias: risk factors for infection and resource utilization. Journal of Surgical Research, 2003; 111 (1): 78-84.

9. Finan KR, Vick CC, Kiefe CI, Neumayer L, Hawn MT. Predictors of wound infection in ventral hernia repair. The American journal of surgery, 2005; 190 (5): 67681.

10. Pessaux P, Lermite E, Blezel E, Msika S, Hay JM, Flamant Y, et al. French Associations for Surgical Research. Predictive risk score for infect-ion after inguinal hernia repair. The American journal of surgery, 2006; 192 (2): 165-71.

11. Iqbal CW, Pham TH, Joseph A, Mai J, Thompson GB, Sarr MG. Long-term outcome of 254 complex incisional hernia repairs using the modified Rives-Stoppa technique. World journal of surgery, 2007; 31 (12): 2398-404.

12. Luijendijk RW, Hop WC, van den Tol MP, de Lange DC, Braaksma MM, IJzermans JN, et al. A comparison of suture repair with mesh repair for inci-sional hernia. New England Journal of Medicine, 2000; 343 (6): 3928.

13. Winfield RD, Bochicchio GV. The critically injured patient: a review and a look ahead. J Am Coll Surg. 2013; 216: 1193-1206.

14. Burger JW, Halm JA, Wijsmular AR, ten Raa S Jakeel. Evaluation of new prosthetic meshes for ventral hernia repair. Surg Endosc. 2006; 20: 1320-5.

15. Tsui C, Klein R, Garabrant M. Minimally invasive surgery: national trends in adoption and future directions 
for hospital strategy. Surg Endosc. 2013; 27: 2253-7.

16. Novitsky YW, Elliot HL, Orestein SB, Rosen MJ.

Trans-versus abdominis muscle release: a novel approach to posterior compartment separation during complex abdominal wall reconstruction. Am J Surg. 2012; 204: 709-716.

17. Marshal JC, Cook DJ, Christou NV et al. Multiple organ dysfunction score: a reliable descriptor of a complex clinical outcome. Crit care med. 1995; 23: 16381652.

18. Ballem N, Parikh R, Berber E, Siperstein A. Laparoscopic versus open ventral hernia repairs: 5 year recurrence rates. Surgical endoscopy, 2008; 22 (9): 1935-40.

19. Ko JH, Wang EC, Salvay DM, Paul BC, Dumanian GA. Abdominal wall reconstruction: lessons learned from 200 "components separation" procedures. Arch Surg. 2009; 144: 1047-1055.

20. Burger JW, Luijendijk RW, Hop WC, Halm JA, Verdaasdonk EG, Jeekel J. Long-term follow-up of a randomized controlled trial of suture versus mesh repair of incisional hernia. Ann Surg. 2004; 240: 578-583.

21. Krpata DM, Blatnik JA, Novitsky YW, Rosen MJ. Evaluation of high-risk, comorbid patients undergoing open ventral hernia repair with synthetic mesh. Surgery, 2013; 153: 120-125.

22. Farrow B, Awad S, Berger DH, Albo D, Lee L, Subramanian $\mathrm{A}$, Bellows $\mathrm{CF}$. More than 150 consecutive open umbilical hernia repairs in a major Veterans Administration Medical Center. The American Journal of Surgery, 2008; 196 (5): 647-51.

23. Kaoutzanis C, Leichtle SW, Mouawad NJ, Welch KB, Lampman RM, Cleary RK. Postoperative surgical site infections after ventral/incisional hernia repair: a comparison of open and laparoscopic outcomes. Surgical endoscopy, 2013; 27 (6): 2221-30.

24. Pierce RA, Spitler JA, Frisella MM, Matthews BD, Brunt LM. Pooled data analysis of laparoscopic vs. open ventral hernia repair: 14 years of patient data accrual. Surgical endoscopy, 2007; 21 (3): 378-86.

25. Funk LM, Perry KA, Narula VK, Mikami DJ, Melvin
WS. Current national practice patterns for inpatient management of ventral abdominal wall hernia in the United States. Surgical endoscopy, 2013; 27 (11): 4104-12.

26. Armañanzas L, Ruiz-Tovar J, Arroyo A, García-Peche P, Armañanzas E, Diez M, Galindo I, Calpena R. Prophylactic mesh vs. suture in the closure of the umbilical trocar site after laparoscopic cholecystectomy in highrisk patients for incisional hernia. A randomized clinical trial. Journal of the American College of Surgeons, 2014; 218 (5): 960-8.

27. van Barneveld KW, Vogels RR, Beets GL, Breukink SO, Greve JW, Bouvy ND, Schreinemacher MH. Prophylactic intraperitoneal mesh placement to prevent incisional hernia after stoma reversal: a feasibility study. Surgical endoscopy, 2014; 28 (5): 1522-7.

28. Kanters AE, Krpata DM, Blatnik JA, Novitsky YM, Rosen MJ. Modified hernia grading scale to stratify surgical site occurrence after open ventral hernia repairs. Journal of the American College of Surgeons, 2012; 215 (6): 787-93.

29. Nguyen MT, Berger RL, Hicks SC, Davila JA, Li LT, Kao LS, Liang MK. Comparison of outcomes of synthetic mesh vs. suture repair of elective primary ventral herniorrhaphy: a systematic review and meta-analysis. JAMA Surg. 2014; 149: 415-21.

30. Porrero JL, Cano-Valderrama O, Marcos A. Um-bilical hernia repair: analysis after 934 procedures. Am Surg. 2015; 81: 899-903.

31. Itani K, Hur K, Kim LT, Anthony T. Veterans Affairs Ventral Incisional Hernia Investigators. Com-parison of laparoscopic and open repair with mesh for the treatment of ventral incisional hernia: a randomized trial. Arch Surg. 2010; 145: 322-8.

32. Hwang CS, Wichterman KA, Alfrey EJ. Laparoscopic ventral hernia repair is safer than open repair: analysis of the NSQIP data. J Surg Res. 2009; 156: 213-6.

33. Warren JA, Cobb IV WS, Carbonell II AM. Modern Management of Abdominal Wall Hernias. Rives. 1992; 258 (7-7): 6-2. 